ISSN 1980-5098@ @()@ DOI: http://dx.doi.org/10.5902/1980509831651

\title{
USO DE FOTOGRAFIAS HEMISFÉRICAS PARA AVALIAÇÃO DA QUALIDADE AMBIENTAL NA MATA DE SANTA GENEBRA, CAMPINAS-SP, BRASIL
}

\author{
USE OF HEMISPHERIC PHOTOGRAPHS FOR THE EVALUATION OF ENVIRONMENTAL \\ QUALITY IN MATA DE SANTA GENEBRA, CAMPINAS/SP STATE, BRAZIL
}

\author{
Joice Machado Garcia ${ }^{1}$ Regina Márcia Longo ${ }^{2}$ Júlio César Penereiro ${ }^{3}$ Deborah Regina Mendes ${ }^{1}$ \\ Paloma Mantovani ${ }^{1}$
}

\begin{abstract}
RESUMO
Atualmente, o desenvolvimento de grandes centros tem exercido pressão constante em remanescentes florestais localizados em áreas urbanas. O estudo dos impactos ambientais aos quais estes são expostos permite a melhor gestão e conservação de remanescentes florestais localizados nestas áreas. Nesse contexto, o presente trabalho teve por objetivo avaliar os impactos da degradação em áreas de borda e do interior da Mata de Santa Genebra, um remanescente florestal constituído $85 \%$ em floresta estacional semidecidual, localizada no distrito de Barão Geraldo (Campinas - SP). Tomaram-se 19 pontos no interior do remanescente, obtendo-se três fotografias para cada ponto, equidistantes 200 metros entre si e cada um a uma distância de 5 metros das trilhas percorridas. Adicionalmente, tomaram-se 40 pontos na área das bordas do remanescente, também abordados em triplicata, equidistantes 200 metros entre si e cada um a uma distância de 10 metros do limite da borda do remanescente florestal. Os resultados permitem concluir que, no inverno, por meio de análises do Índice de Área Foliar, a borda do remanescente florestal encontra-se mais degradada que o seu interior, inclusive apontando os locais cuja degradação apresentou-se mais pronunciada, necessitando de ações mais emergenciais para sua recuperação. Esses resultados são provavelmente decorrentes das influências antropogênicas sofridas nos trechos trabalhados da mata estudada.
\end{abstract}

Palavras-chave: degradação ambiental; índice de área foliar; remanescente florestal.

\begin{abstract}
Currently, the development of large centers has exerted constant pressure on the remaining forests located in urban areas. The study of environmental impacts to which they are exposed allows better management and conservation of forest remnants located in this areas. In this context, the present study aimed to evaluate the impacts of degradation in forest border areas and inside of Mata de Santa Genebra, a forest remnant constituted $85 \%$ of semideciduous forest, located in Barão Geraldo district (Campinas, SP). They took up 19 points within the remaining, three photos were taken for each point, equidistant 200 meters from each other and each at a distance of 5 meters from the traversed tracks. Additionally, 40 points in the remainder of the edge area, also discussed in triplicate, equally spaced 200 meters apart and each at a distance of 10 meters from the edge of the forest fragment. The results lead to the conclusion that in the winter, through the Leaf Area Index analyzes, the edge of the remaining forest is more degraded in the interior, including point out of the places where degradation had become more pronounced and they need more emergency actions for their

1 Graduanda em Engenharia Sanitária e Ambiental, Pontifícia Universidade Católica de Campinas, Rod. Dom Pedro I, km 136, CEP 13086-900, Campinas (SP), Brasil. joicegarcia@puccampinas.edu.br/ deborah.rm@puccampinas. edu.br / paloma.m@puccampinas.edu.br

2 Engenheira Agrônoma, Dra., Professora da Faculdade de Engenharia Sanitária e Ambiental e Programa de PósGraduação em Infraestrutura Urbana, Pontifícia Universidade Católica de Campinas, Rod. Dom Pedro I, km 136, CEP 13086-900, Campinas (SP), Brasil.regina.longo@puc-campinas.edu.br

3 Bacharel em Física, Dr., Professor da Faculdade de Engenharia Sanitária e Ambiental e Programa de PósGraduação em Infraestrutura Urbana, Pontifícia Universidade Católica de Campinas, Rod. Dom Pedro I, km 136, CEP 13086-900, Campinas (SP), Brasil.jcp@puc-campinas.edu.br
\end{abstract}


recovery. These results are probably due to anthropogenic influences present in the studied forest stretches. Keywords: environmental degradation; leaf area index; remaining forest.

\section{INTRODUÇÃO}

As áreas florestais, além de se apresentarem extremamente importantes dentro do contexto urbano, também representam um referencial urbanístico de cunho social, político, econômico, arquitetônico e paisagístico (BADIRU, 2005). Segundo Paiva e Gonçalves (2002), estas áreas estão relacionadas a diversos aspectos ambientais, tais como retenção e estabilização do solo, prevenção de processos erosivos, proteção das margens dos cursos d'água, manutenção da temperatura adequada às diversas espécies de peixes e outros organismos aquáticos, minimização dos ruídos urbanos e integração da paisagem urbana.

Sabe-se, por meio de estudos realizados em florestas naturais, que os maciços florestais são importantes na regulação do clima em escala mundial, além de evidenciarem as graves consequências da devastação florestal para a fertilidade do solo e para o suprimento de água no planeta (LAMPRECHT, 1990).

Ao longo das últimas décadas percebeu-se um aumento na degradação das florestas tropicais e subtropicais em várias regiões do planeta, devido a processos de estruturação e à expansão dos centros urbanos e industriais, bem como à expansão agrícola. A partir da constatação dos impactos ambientais, decorrentes dessa degradação, observou-se a importância na manutenção e preservação de áreas verdes, próximas ou inclusas nos centros urbanos, pois estas influenciam consideravelmente na qualidade de vida da população como um todo e também de outras espécies a elas associadas.

Sendo assim, o monitoramento da paisagem, realizado por meio da análise da cobertura vegetal, é fator primordial no planejamento de uso e ocupação do solo, face principalmente à velocidade de apropriação do espaço físico e ao pouco conhecimento dos recursos naturais nele existentes. Constata-se, portanto, que o mapeamento da cobertura vegetal em uma dada região é de extrema importância para a compreensão do espaço e das mudanças ocorridas, uma vez que o meio ambiente naquele local está em constante transformação. Etto et al. (2013) e Fengler et al. (2015) desenvolveram trabalhos de avalição da degradação ambiental de remanescentes florestais localizados em bacias hidrográficas urbanas, destacando a importância desses no contexto da qualidade ambiental das cidades.

A Área de Relevante Interesse Ecológico (ARIE) Mata de Santa Genebra é o maior remanescente florestal do município de Campinas - SP, no entanto, ela conserva poucas características intrínsecas de seu habitat original devido às perdas ocorridas ao longo do processo de ocupação do município. Em grande parte, esta área remanescente estabelecida em 05 de novembro de 1985, está cercada por uma matriz inóspita, visto que a maioria dos seus organismos e suas partes adjacentes estão propensas a uma variedade de modificações físicas e bióticas, relacionadas ao processo denominado efeito de borda (PRIMACK, 2006). Alguns trabalhos realizados nas áreas de borda apontam para as principais interferências que o remanescente vem sofrendo, bem como para os principais danos promovidos pelas ações antrópicas desses entornos (LONGO et al., 2015; CHUDNOBSKY et al., 2015; DAMAME et al., 2015).

A avaliação da qualidade de um remanescente florestal pode ser realizada utilizando-se fotografias hemisféricas que, de acordo com Zhang et al. (2005), são capazes de capturar os padrões de obstrução e penetração da luz em um dossel, sendo que a arquitetura da copa e a área de folhagem podem ser quantificadas. Ainda segundo os mesmos autores, por meio deste procedimento é viável determinar a capacidade de discriminação espacial do dossel, possibilitando adquirir a distribuição angular das folhagens e de quantificação em frações de falhas ("gap fractions") em diferentes ângulos zenitais e azimutais, sendo essas algumas das vantagens dessa técnica. Ao mesmo tempo, esse tipo de procedimento oferece um permanente arquivo fotográfico, sendo uma fonte de posição, tamanho, densidade e distribuição das aberturas no dossel no momento da captura da imagem (HEMIVIEW, 2015).

Desta forma, o objetivo do presente trabalho é fazer uma avaliação da qualidade ambiental na área em questão, utilizando-se de fotografias hemisféricas da cobertura vegetal em pontos localizados no interior e na borda do remanescente florestal. Espera-se que essa investigação forneça importantes informações adicionais das condições da Mata de Santa Genebra e, ao mesmo tempo, possa auxiliar os gestores de restauração florestal e manejo, além de averiguar o cenário atual sobre o comportamento do meio ambiente 
naquele local e das possíveis pressões sofridas pelas ocupações das áreas do entorno.

\section{MATERIAL E MÉTODO}

\section{Caracterização da área de estudo}

De acordo com o Plano de Manejo elaborado pelo Ministério do Meio Ambiente do Brasil, a Mata de Santa Genebra é a segunda maior floresta urbana do Brasil, sendo apenas superada pela Floresta da Tijuca, no Rio de Janeiro. Ela está localizada na bacia hidrográfica do Ribeirão das Pedras e Ribeirão do Quilombo, a noroeste do município de Campinas, estado de São Paulo. Esse remanescente é constituído por $85 \%$ de floresta estacional semidecidual e os outros $15 \%$ de floresta higrófila, ou seja, de floresta de brejo. A coleta do solo do remanescente aqui estudado, constitui de amostras com $80 \%$ por Latossolo VermelhoEscuro álico textura argilosa, e os outros $20 \%$ de Podzólico Vermelho Amarelo Distrófico textura médioargilosa com inserções de solos hidromórficos (“Glei”). (BRASIL, 2010).

A Figura 1a mostra a localização geográfica da ARIE, cuja entrada de acesso está localizada na Rua Mata Atlântica, $n^{\circ}$. 447, no bairro Bosque de Barão, Distrito Barão Geraldo, em Campinas - SP, sendo suas coordenadas geográficas identificadas como: latitude $22^{\circ} 44^{\prime} 45^{\prime \prime} \mathrm{S}$ e longitude $47^{\circ} 06^{\prime} 33^{\prime}$ ' W. A área deste remanescente é de 251,77 ha, com altitude média de $670 \mathrm{~m}$, temperatura média anual de $20,6^{\circ} \mathrm{C}$ e perímetro de aproximadamente $9 \mathrm{~km}$ (BRASIL, 2010). Em geral, as árvores que a compõem são altas, contendo espécies que alcançam mais de $25 \mathrm{~m}$, como o jequitibá-rosa, a peroba-rosa e o jatobá (BRASIL, 2010).

No intuito de realizar uma avaliação das condições e diferenças entre as áreas interna e externa da mata optou-se por fazer imagens fotográficas em pontos no interior e na borda do remanescente florestal, como mostrado na Figura 1b. Esta figura revela os pontos fotografados no interior da mata, identificados por letras de " $A$ " até " $S$ ", sendo a trilha - I os pontos marcados de " $A$ " a " $F$ ", a trilha - II, os pontos de " $G$ " a " $K$ " e a trilha - III os pontos de " $L$ " a " $S$ ". Os pontos fotografados ao longo da borda da mata foram numerados de 1 a 40: os pontos marcados de 1 a 10 se referem ao "trecho - a" e encontram-se próximos à área urbana; os pontos de 11 a 20 ("trecho - b") se referem aos locais próximos à área agrícola; os pontos de 21 a 30 ("trecho - c") e de 31 a 40 ("trecho - d") se encontram próximos às áreas de pastagem e agrícola, respectivamente.

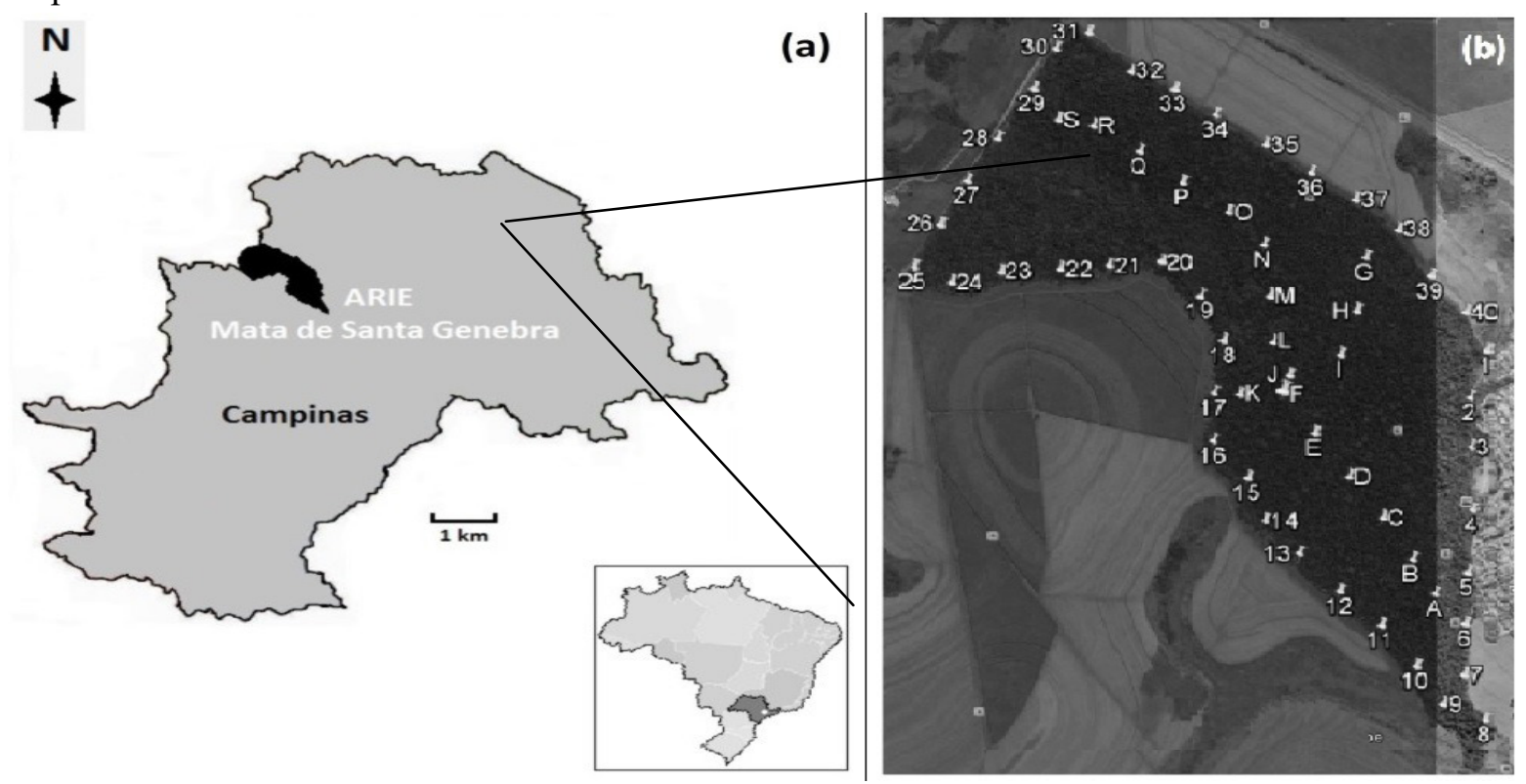

FIGURA 1: a) Localização geográfica da ARIE Mata de Santa Genebra em Campinas - SP, Brasil; b) Pontos selecionados no interior (letras) e na borda (números) da Mata de Santa Genebra (Adaptado de: <www. google.com.br/maps $>$ ).

FIGURE 1: a) Geographical location of the ARIE Mata de Santa Genebra in Campinas, SP state, Brazil; b) Selected points within (letters) and on the edge (numbers) of Mata de Santa Genebra (Adapted from: <www. google.com.br/maps $>$ ). 


\section{Obtenção de dados}

Foram utilizadas fotografias hemisféricas para se obterem os valores de Índice de Área Foliar (IAF) da região analisada. Esse índice caracteriza-se como um importante atributo estrutural de um determinado tipo de cobertura arbórea, haja visto que é no dossel que ocorrem significativos processos no ecossistema, como: transpiração, interceptação da chuva, fotossíntese e fornecimento de matéria orgânica para a serrapilheira (GALVANI; LIMA, 2014).

Os valores de IAF foram obtidos com a aplicação do software HemiView C (HEMIVIEW, 2015). Este, configurado com a data de tiragem da fotografia, juntamente com as coordenadas geográficas das mesmas, foi possível analisar e classificar a quantidade de luz (pixels brancos) e a biomassa vegetal (pixels negros) em anéis de largura definida. Para isso, o brilho de cada pixel da foto é calculado em função de uma média de três canais de cores (vermelho, verde e azul) e transformado em uma escala de cinza. Em função da amostragem ser realizada em uma unidade de conservação (Área de Relevante Interesse Ecológico - AIRE Mata de Santa Genebra) optouse pela não realização de amostragem destrutiva. Segundo os resultados obtidos por Rody et al. (2014), as fotos hemisféricas apresentaram bons resultados para obtenção do IAF quando comparadas a métodos destrutivos indicando o uso potencial nestas estimativas.

Ressalta-se que o procedimento fotográfico adotado fornece imagem com um extremo ângulo de visão, geralmente de $180^{\circ}$, tendo como resultado uma projeção do hemisfério em um plano. A exata natureza dessa projeção varia de acordo com a lente da objetiva utilizada. Como descreveu Jonckheere (2004), lentes com uma perfeita projeção equiangular, isto é, com $180^{\circ}$ de campo de visão, resultam em uma imagem circular que mostra uma visão completa do céu em todas as direções, com o zênite no centro e o horizonte nas bordas da imagem. No intuito de ajustar a melhor posição da câmera fotográfica, foram realizados testes preliminares em relação às configurações padrão. Para tanto, o ângulo utilizado ao realizar as fotos foi padronizado em relação ao Norte da Terra, sendo este determinado por meio do uso de uma bússola magnética manual.

A título de exemplo dos procedimentos adotados durante a coleta de dados, a Figura 2 revela duas situações distintas obtidas com o equipamento fotográfico. A Figura 2a mostra uma fotografia do interior da mata obtida no ponto " $B$ " (trilha - I). Percebe-se que há uma baixa visibilidade do céu devido às folhagens, o que propicia boa cobertura do solo e, consequentemente, uma interceptação de luz eficiente; ponto-chave para altas taxas fotossintéticas e bom desenvolvimento da mata, além de um aporte de material orgânico ao solo. Em contrapartida, a Figura 2b, relativa ao ponto " 13 " localizado na borda da mata ("trecho - b"), apresenta uma situação oposta à discutida anteriormente. Neste caso, tem-se representada a alta visibilidade do céu e, consequentemente, uma área degradada do solo e com vegetação não densa no dossel.

Cada vez que a máquina fotográfica foi fixada em um ponto, tomaram-se três imagens para efeito de comparação e eliminação de possíveis erros, acarretando um total de 57 fotos no trecho interno (trilhas: I - Barone-1, II - Central e III - Barone-2) e de 120 fotos na borda da mata (trechos - a, - b, - c, - d).

Além de se obterem as fotografias, foram anotadas as coordenadas de cada local fotografado, baseando-se no sistema de projeção UTM que, por sua vez, utiliza o plano cartesiano e o metro como unidade de distâncias dos pontos trabalhados, com o auxílio de um Global Positioning System (GARMIN, modelo GPSMAP 76S) configurado em UTM e Datum WGS84. As Tabelas 1 e 2 mostram as coordenadas longitude (E) e latitude (N) em UTM, além da elevação (Elev.), de todos os pontos nas trilhas e trechos, respectivamente, tratados neste estudo. 

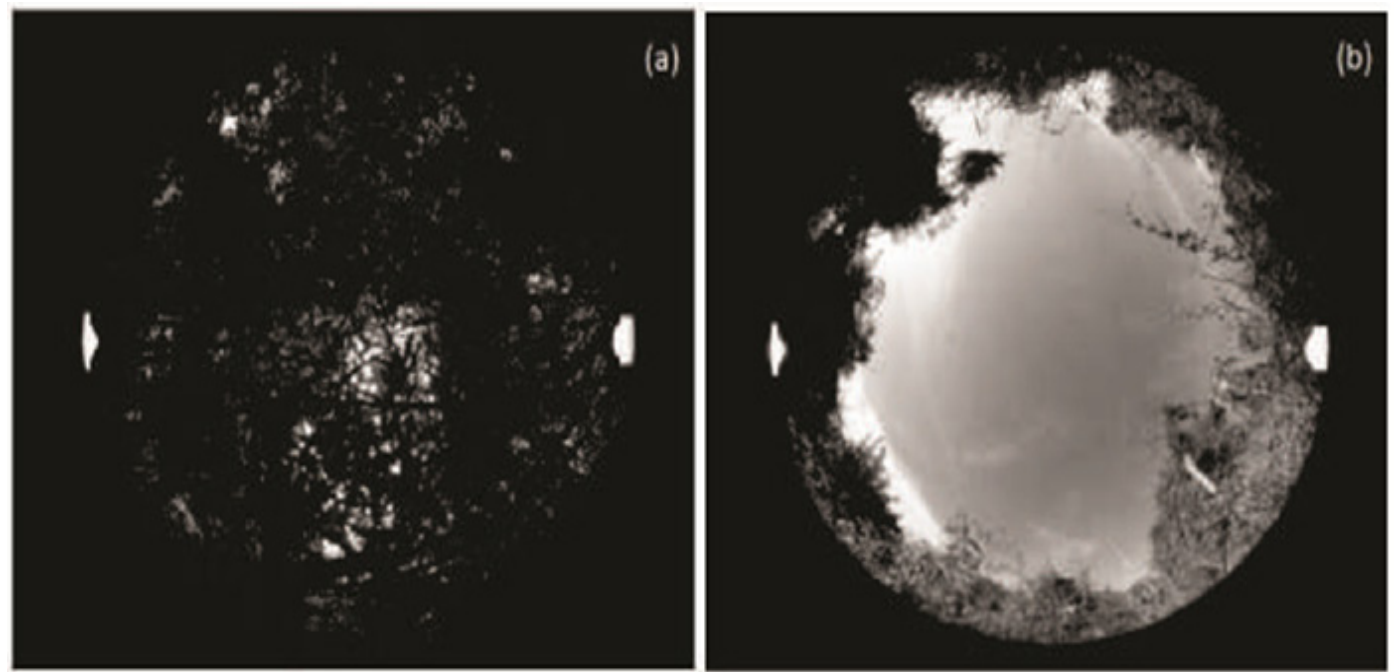

FIGURA 2: Fotografia hemisférica da Mata de Santa Genebra: a) ponto interno (posição “ $B$ ”), b) ponto da borda (\#13).

FIGURE 2: Hemispheric photography in Mata de Santa Genebra: a) internal point (position “ $B$ ”), b) on the edge (\#13).

TABELA 1: Localização dos pontos selecionados no interior da Mata de Santa Genebra.

TABLE 1: Location of selected points within Mata de Santa Genebra.

\begin{tabular}{|c|c|c|c|c|}
\hline \multirow{2}{*}{ Trilha } & \multirow{2}{*}{ Ponto } & \multicolumn{3}{|c|}{ Coordenadas em UTM - Fuso $23 \mathrm{~S}$} \\
\hline & & E (Longitude) & $\mathrm{N}$ (Latitude) & Elev. (m) \\
\hline \multirow{6}{*}{ I } & A & 7473667 & 283803 & 609 \\
\hline & $\mathrm{B}$ & 7473806 & 283716 & 611 \\
\hline & $\mathrm{C}$ & 7473967 & 283605 & 612 \\
\hline & $\mathrm{D}$ & 7474127 & 283480 & 620 \\
\hline & E & 7474298 & 283353 & 621 \\
\hline & $\mathrm{F}$ & 7474454 & 283229 & 617 \\
\hline \multirow{5}{*}{ II } & G & 7475003 & 283530 & 620 \\
\hline & $\mathrm{H}$ & 7474787 & 283502 & 618 \\
\hline & I & 7474610 & 283443 & 616 \\
\hline & $\mathrm{J}$ & 7474527 & 283255 & 612 \\
\hline & K & 7474446 & 283073 & 614 \\
\hline \multirow{8}{*}{ III } & $\mathrm{L}$ & 7474659 & 283195 & 607 \\
\hline & M & 7474844 & 283181 & 608 \\
\hline & $\mathrm{N}$ & 7475049 & 283154 & 599 \\
\hline & $\mathrm{O}$ & 7475179 & 283022 & 588 \\
\hline & $\mathrm{P}$ & 7475297 & 282850 & 595 \\
\hline & Q & 7475421 & 282688 & 597 \\
\hline & $\mathrm{R}$ & 7475521 & 282513 & 597 \\
\hline & S & 7475607 & 282324 & 593 \\
\hline
\end{tabular}

Em que: E e N representam as coordenadas em UTM; Elev. representa a elevação do local. 
TABELA 2: Localização dos pontos selecionados na borda da Mata de Santa Genebra.

TABLE 2: Location of selected points on the edge of Mata de Santa Genebra.

\begin{tabular}{|c|c|c|c|c|c|c|c|c|c|}
\hline Trecho & Ponto & $\begin{array}{c}\mathrm{E} \\
\text { (Longitude) }\end{array}$ & $\begin{array}{c}\mathrm{N} \\
\text { (Latitude) }\end{array}$ & Elev. (m) & Trecho & Ponto & $\begin{array}{c}\mathrm{E} \\
\text { (Longitude) }\end{array}$ & $\begin{array}{c}\mathrm{N} \\
\text { (Latitude) }\end{array}$ & Elev. (m) \\
\hline \multirow{10}{*}{$\mathrm{a}$} & 1 & 7474637 & 283985 & 600 & \multirow{10}{*}{$b$} & 11 & 7473537 & 283605 & 610 \\
\hline & 2 & 7474448 & 283922 & 606 & & 12 & 7473672 & 283451 & 613 \\
\hline & 3 & 7474250 & 283928 & 613 & & 13 & 7473820 & 283301 & 614 \\
\hline & 4 & 7474002 & 283935 & 618 & & 14 & 7473949 & 283175 & 612 \\
\hline & 5 & 7473753 & 283919 & 621 & & 15 & 7474117 & 283105 & 611 \\
\hline & 6 & 7473550 & 293914 & 619 & & 16 & 7474261 & 282980 & 616 \\
\hline & 7 & 7473344 & 283914 & 614 & & 17 & 7474453 & 282979 & 615 \\
\hline & 8 & 7473167 & 283995 & 603 & & 18 & 7474661 & 283010 & 604 \\
\hline & 9 & 7473227 & 283841 & 600 & & 19 & 7474839 & 282922 & 596 \\
\hline & 10 & 7473378 & 283735 & 604 & & 20 & 7474975 & 282775 & 601 \\
\hline \multirow{10}{*}{$\mathrm{c}$} & 21 & 7474957 & 282583 & 610 & \multirow{10}{*}{ d } & 31 & 7475900 & 282487 & 598 \\
\hline & 22 & 7474939 & 282404 & 613 & & 32 & 7475652 & 282652 & 603 \\
\hline & 23 & 7474923 & 282181 & 614 & & 33 & 7475671 & 282814 & 608 \\
\hline & 24 & 7474880 & 282000 & 613 & & 34 & 7475569 & 282970 & 607 \\
\hline & 25 & 7474941 & 281859 & 607 & & 35 & 7475451 & 283156 & 607 \\
\hline & 26 & 7475115 & 281953 & 601 & & 36 & 7475341 & 283325 & 610 \\
\hline & 27 & 7475293 & 282048 & 589 & & 37 & 7475235 & 283492 & 613 \\
\hline & 28 & 7475468 & 282153 & 588 & & 38 & 7475113 & 283650 & 611 \\
\hline & 29 & 7475671 & 282284 & 594 & & 39 & 7474930 & 283775 & 612 \\
\hline & 30 & 7475836 & 282368 & 597 & & 40 & 7474789 & 283904 & 611 \\
\hline
\end{tabular}

Em que: E e N representam as coordenadas em UTM; Elev. representa a elevação do local.

\section{Análises realizadas}

O parâmetro tomado para comparação do efeito de degradação na borda com o interior da mata foi o IAF. Esse índice, utilizado para descrever a superfície fotossintética da copa das plantas, é definido como a quantidade de área da superfície foliar por unidade de área do solo, sendo, portanto, expresso em $\mathrm{m}^{2} / \mathrm{m}^{2}$. No entanto, constata-se recentemente a definição de IAF como sendo a metade da área total da folhagem por unidade de área da superfície do solo HemiView@ (HEMIVIEW, 2015). Vale destacar ainda, que, apesar do IAF em sua definição estar relacionado apenas à área das folhas, o método utilizado não faz essa diferenciação, considerando em sua análise também os galhos, flores e frutos. Contudo, apesar de todas as limitações associadas a este método indireto para a avaliação dos dosséis florestais (ROXBURGH; KELLY, 1995; JENNINGS et al., 1999) a fotografia hemisférica fornece uma ferramenta importante e útil em estudos ecológicos (GALVANI; LIMA, 2014).

Para fins de correlação com o IAF, utilizaram-se dados de teor de Matéria Orgânica (MO) e índice de vermelho do solo (RR). Optou-se por essas correções uma vez que as alterações no material vegetal presentes nos elementos arbóreos podem refletir em características importantes de solo como o teor de MO e no índice do RR. Essas alterações em parâmetros de solo podem ser utilizadas também na discussão da qualidade ambiental das áreas de bordas do remanescente em estudo e estão diretamente associadas com a qualidade e quantidade do material orgânico incorporado ao solo. Após a obtenção dos dados foram realizadas análises de correção entre IAF-MO, IAF-RR e MO-RR.

Os valores de matéria orgânica foram obtidos por meio de amostragens de solo coletadas em profundidade de 0 a $0,20 \mathrm{~m}$ nos pontos em estudo, segundo o procedimento adotado em Lemos e Santos (1996) e Mendes et al. (2013), sendo analisados segundo a EMBRAPA (2011). Para obtenção da cor do solo, as amostras obtidas foram comparadas com Munsell Soil Color Charts ("Carta de Munsell") (MUNSELL SOIL COLOR COMPANY, 1975). 
Por se tratar de dados qualitativos, a obtenção de cor das amostras baseada na Carta de Munsell foi transformada em dados ordinais para que a análise pudesse ser realizada. Assim, os valores, cromas e matizes das amostras foram utilizados no cálculo do Índice de Vermelho do Solo (RR), seguindo o procedimento de Torrent e Barrón (2011), expresso por:

$$
R R=[(10-H) \cdot C] / V
$$

Nesta equação, $\mathrm{V}$ representa o valor, $\mathrm{C}$ significa a croma e $\mathrm{H}$ é o número do matiz da Carta de Munsell. O último fator representa o número que precede as letras YR da referida carta.

\section{Análise estatística dos dados}

De posse dos dados observados, os mesmos foram organizados e tratados em planilhas do aplicativo Microsoft Office Excel, o que possibilitou a realização de cálculos estatísticos, em particular usando a estatística descritiva para cálculos de média, mediana, desvio padrão, coeficiente de variação, coeficiente de correlação, o teste de Kruskal-Wallis e o teste conhecido como valor "p" (FREUND, 2006), visando detectar eventuais ocorrências de correlação entre os parâmetros IAF, MO e RR, além da geração de gráficos. Em função do número de pontos amostrados, optou-se por não realizar análises geoespaciais, pois os parâmetros ambientais florestais apresentam alta heterogeneidade. Segundo Souza e Souza (2011), um número de pontos inferior a 100 não é aconselhável na espacialização de algumas análises do solo por krigagem, já que apresentam um incremento nítido no erro da estimativa.

O teste Kruskal-Wallis, também conhecido como teste $H$, é um método que serve para testar a suposição de que $k$ amostras aleatórias independentes provêm de populações idênticas e, em particular, a hipótese nula de que $\mu_{1}=\mu_{2}=\cdots=\mu_{k}$ contra a hipótese alternativa de que essas médias não são todas iguais. Esse procedimento não exige a suposição de que as populações amostradas tenham, pelo menos aproximadamente, distribuições normais. De acordo com Freund (2006), o referido teste é baseado na estatística:

$$
H=\frac{12}{n(n+1)} \sum_{i=1}^{k} \frac{R_{i}^{2}}{n_{i}}-3(n+1)
$$

Sendo $R_{i}$ a soma dos postos atribuídos aos $n_{i}$ valores da i-ésima amostra e $n=n_{1}+n_{2}+\cdots+n_{k}$ . Se a hipótese nula é verdadeira e se cada amostra possui, pelo menos, cinco observações, em geral é considerado razoável aproximar a distribuição amostral de $H$ por uma distribuição qui-quadrado com $k-1$

graus de liberdade. Consequentemente, rejeita-se a hipótese nula $\mu_{1}=\mu_{2}=\cdots=\mu_{k}$, e não se rejeita a hipótese alternativa de que essas médias não são todas iguais, quando o valor obtido para $H$ é maior que ou

igual a $\chi_{\alpha}^{2}$ para $k-1$ graus de liberdade (FREUND, 2006).

O teste dos valores "p" é o método usado quando não é possível especificar o nível de significância de uma amostra. O referido valor "p" é reconhecido como o menor nível de significância para a qual a hipótese nula possa ser rejeitada.

\section{RESULTADOS E DISCUSSÃO}

A Tabela 3 apresenta os valores médios obtidos para IAF, MO e RR nos pontos localizados no interior da mata de Santa Genebra, além da estatística descritiva para os valores encontrados. Pela análise dos dados é possível verificar que o IAF para os pontos do interior apresentou para a trilha - I valores entre 1,328 e $3,522 \mathrm{~m}^{2} / \mathrm{m}^{2}$, para a trilha - II entre 0,955 e $2,766 \mathrm{~m}^{2} / \mathrm{m}^{2}$ e para a trilha - III entre 1,166 e $2,953 \mathrm{~m}^{2} / \mathrm{m}^{2}$.

A grandeza IAF pode variar de um ecossistema para outro, dependendo das condições de cada local, em particular do suprimento de água e da fertilidade do solo que estabelecem a estrutura e composição florística do dossel. A dinâmica do IAF de uma cobertura vegetal nativa/natural pode ser entendida como resultante de respostas ecofisiológicas das plantas às condições química, física e biológica do solo, além das condições bióticas (clima, principalmente a precipitação pluvial) e à interdependência desses fatores nos diferentes estágios sucessionais da vegetação (VILANI, 2009). 
TABELA 3: Registros de IAF, MO e RR medidos nos pontos do interior na Mata de Santa Genebra.

TABLE 3: IAF, MO and RR records measured in the internal points of Mata de Santa Genebra.

\begin{tabular}{|c|c|c|c|c|}
\hline Trilha & Ponto & $\operatorname{IAF}\left(\mathrm{m}^{2} / \mathrm{m}^{2}\right)$ & $\mathrm{MO}\left(\mathrm{g} / \mathrm{dm}^{3}\right)$ & RR \\
\hline \multirow{6}{*}{ I } & A & 1,328 & 43 & 5,000 \\
\hline & $\mathrm{B}$ & 3,522 & 31 & 3,333 \\
\hline & $\mathrm{C}$ & 1,876 & 33 & 9,000 \\
\hline & $\mathrm{D}$ & 2,741 & 47 & 7,500 \\
\hline & $\mathrm{E}$ & 1,717 & 45 & 5,000 \\
\hline & $\mathrm{F}$ & 1,864 & 45 & 10,000 \\
\hline Média & & 2,175 & 40,667 & 6,639 \\
\hline Mediana & & 1,870 & 44,000 & 6,250 \\
\hline Desvio Padrão & & 0,806 & 6,860 & 2,604 \\
\hline Coef. de Variação (\%) & & 37,06 & 16,87 & 39,23 \\
\hline \multirow{5}{*}{ II } & $\mathrm{G}$ & 2,556 & 32 & 10,000 \\
\hline & $\mathrm{H}$ & 2,094 & 40 & 5,000 \\
\hline & I & 1,816 & 37 & 7,500 \\
\hline & $\mathrm{J}$ & 2,766 & 56 & 7,500 \\
\hline & $\mathrm{K}$ & 0,955 & 39 & 11,250 \\
\hline Média & & 2,037 & 40,800 & 8,250 \\
\hline Mediana & & 2,094 & 39,000 & 7,500 \\
\hline Desvio Padrão & & 0,711 & 9,039 & 2,437 \\
\hline Coef. de Variação (\%) & & 34,91 & 22,15 & 29,54 \\
\hline \multirow{8}{*}{ III } & $\mathrm{L}$ & 1,946 & 45 & 5,000 \\
\hline & M & 1,166 & 35 & 6,667 \\
\hline & $\mathrm{N}$ & 2,733 & 74 & 2,000 \\
\hline & $\mathrm{O}$ & 1,885 & 38 & 1,000 \\
\hline & $P$ & 2,285 & 30 & 2,500 \\
\hline & Q & 2,953 & 25 & 1,875 \\
\hline & $\mathrm{R}$ & 1,823 & 25 & 7,500 \\
\hline & $\mathrm{S}$ & 1,812 & 21 & 3,750 \\
\hline Média & & 2,075 & 36,625 & 3,786 \\
\hline Mediana & & 1,916 & 32,500 & 3,125 \\
\hline Desvio Padrão & & 0,568 & 17,029 & 2,385 \\
\hline Coef. de Variação (\%) & & 27,38 & 46,49 & 62,99 \\
\hline
\end{tabular}

Em que: $\mathrm{IAF}=$ İndice de Área Foliar; MO = Matéria Orgânica; $\mathrm{RR}=$ Índice de Vermelho do Solo; Coef. = Coeficiente.

Para os teores de MO observa-se que, na trilha - I, os valores ficaram entre 31 e $47 \mathrm{~g} / \mathrm{dm}^{3}$, na trilha - II, entre 32 e $56 \mathrm{~g} / \mathrm{dm}^{3}$ e, na trilha - III, entre 21 e $74 \mathrm{~g} / \mathrm{dm}^{3}$. Portanto, constata-se que a maior variação foi verificada na trilha - III, coincidentemente, a região que apresenta maior quantidade de pontos. De modo geral, pode-se observar que o teor de matéria orgânica do solo é dependente de muitos fatores que exercem sua influência individualmente e em conjunto, tais como: clima, textura do solo, topografia, drenagem, cobertura vegetal e uso da terra. Segundo Guerra (1990), o processo de formação de matéria orgânica no solo é inicialmente um processo biológico, sendo que quase toda a flora e a fauna existentes no solo têm um efeito direto ou indireto sobre o mesmo. Uma parte considerável de matéria orgânica no solo é formada por raízes e microrganismos. Como uma regra geral, os constituintes minerais do solo são essenciais na formação de húmus, porque os efeitos químicos dessa matéria orgânica podem reagir com as substâncias minerais para formar o chamado complexo argila-húmus (GUERRA, 1990). Neste contexto insere-se a importância de associação entre os teores da matéria orgânica presente no solo daqueles oriundos da cobertura vegetal.

Juntamente com a obtenção do IAF, analisou-se a cor do solo, buscando relacionar a presença de 
óxidos de ferro com o teor de matéria orgânica. A matéria orgânica confere cores escuras tanto aos horizontes superficiais como aos horizontes subsuperficiais. Assim, cores vermelhas, amarelas e brunadas são atribuídas à presença de óxidos de ferro, enquanto que a presença de cores acinzentadas está relacionada aos ambientes de redução e remoção dos óxidos de ferro, em condições hidromórficas. Cores avermelhadas são atribuídas à presença de hematita, ao passo que os índices de vermelho são propostos para quantificar este óxido de ferro em solos. No entanto, solos ricos em quartzo e pobres em matéria orgânica e óxidos de ferro apresentam cores claras e esbranquiçadas (BOTELHO et al., 2006).

Neste trabalho foram obtidos os seguintes valores para o índice de vermelho (RR): para a trilha - I, entre 3,333 e 10,000, para a trilha - II, entre 5,000 e 11,250 e para a trilha - III, entre 1,000 e 7,500. Esses valores indicam um solo bastante diversificado, isto é, com características de três classificações de solos assim especificadas: amarelos, vermelho-amarelos e vermelhos. Entretanto, os dados apresentados na Tabela 3 indicam a predominância de solo com padrão vermelho. Isso encontra-se em conssonância com o estudo realizado por Aguiar (1995), que determinou, em amostras coletadas de solo do remanescente em estudo, que $80 \%$ é constituido por Latossolo Vermelho-Escuro álico textura argilosa, sendo os outros 20 $\%$ restantes constituídos por Podzólico Vermelho Amarelo Distrófico textura médio-argilosa com inserções de solos hidromórficos.

Analogamente, a Tabela 4 resume os valores médios obtidos para a borda da mata, sendo detectados os seguintes valores para o IAF nas diferentes bordas analisadas: no trecho - a, entre 1,032 e 2,228 $\mathrm{m}^{2} /$ $\mathrm{m}^{2}$, no trecho - b, entre 0,741 e $1,536 \mathrm{~m}^{2} / \mathrm{m}^{2}$, no trecho - c, entre 0,754 e $3,120 \mathrm{~m}^{2} / \mathrm{m}^{2}$ e no trecho - d, entre 1,434 e 2,346 $\mathrm{m}^{2} / \mathrm{m}^{2}$. Constata-se nesta tabela, que algumas áreas, particularmente no trecho - b e no trecho - c, apresentaram os menores valores para IAF. Isso se deve à existência de clareiras de diferentes idades e tamanhos, originadas tanto da extração seletiva de madeiras nobres, quanto do corte raso para aproveitamento de lenha em alguns trechos restritos. Contudo, foram também nos pontos " 30 " e " 25 " do trecho - c que se registraram os maiores valores de IAF, possivelmente devido à irregularidade e inconstância da mata em estudo. Em contraste com as áreas de manejo, áreas bastante vegetadas foram encontradas neste mesmo trecho, possibilitando a detecção de uma grande variação nos valores de IAF. Outro problema detectado, também em função do histórico de eventos ocorridos na mata, foi a ocorrência de quedas de indivíduos provenientes de ventos, raios e incêndios, principalmente nas áreas de borda.

Comparando-se as três metodologias de estimativas de IAF, sendo aplicados os procedimentos de Lambert-Beer (método direto), do Moderate-Resolution Imaging Spectroradiometer (MODIS) e de fotografias hemisféricas, Sanches et al. (2008) encontraram para a floresta de transição Amazônia-Cerrado entre 2001 e 2005 que o IAF estimado por Lambert-Beer apresentou sazonalidade e uma média anual variando de 3,21 a $3,74 \mathrm{~m}^{2} / \mathrm{m}^{2}$ no período de 2001 a 2003 , enquanto que o IAF estimado pelo produto MODIS variou de 5,25 a $5,54 \mathrm{~m}^{2} / \mathrm{m}^{2}$ no mesmo período, ao passo que o IAF estimado por fotografias hemisféricas variou de 3,05 a $4,12 \mathrm{~m}^{2} / \mathrm{m}^{2}$ entre Junho/2004 a Maio/2005. Portanto, constata-se que os valores encontrados para IAF pelos métodos direto e por fotografias hemisféricas revelaram valores muito parecidos, o que significa ser viável a utilização de fotografias hemisféricas para determinação do IAF no estudo de uma determinada floresta, sendo os valores ligeiramente subestimados quando utilizadas as fotografias hemisféricas. Por se tratar de um experimento realizado no interior de uma unidade de conservação, optou-se no presente estudo pela utilização apenas de fotografias hemisféricas.

Para os resultados obtidos para o teor de MO observou-se valores para o trecho - a entre 40 e 67 $\mathrm{g} / \mathrm{dm}^{3}$, no trecho - b entre 34 e $66 \mathrm{~g} / \mathrm{dm}^{3}$, no trecho - c entre 36 e $67 \mathrm{~g} / \mathrm{dm}^{3}$ e no trecho - d entre 37 e $60 \mathrm{~g} /$ $\mathrm{dm}^{3}$. Na determinação das classes do solo pelo teor de matéria orgânica, segundo o Instituto Agronômico de Campinas (2015), a área da borda da mata estudada se enquadra predominantemente nos limites da classificação de solo argiloso, isto é, entre 31 e $60 \mathrm{~g} / \mathrm{dm}^{3}$, o que corresponde a $85 \%$ do solo coletado. Destaca-se que os restantes $15 \%$ do solo apresentaram acúmulo de matéria orgânica, fator prejudicial ao desenvolvimento do meio. Não obstante, no interior da referida mata, o solo é predominantemente argiloso, correspondendo a $74 \%$ dessa área total. Os $26 \%$ restantes dividem-se em solos de textura média (21\%), e solos com acúmulo de matéria orgânica (5\%). 
TABELA 4: Registros de IAF, MO e RR medidos nos pontos da borda da Mata Santa Genebra.

TABLE 4: IAF, MO and RR records measured on the edge of Mata de Santa Genebra.

\begin{tabular}{|c|c|c|c|c|c|c|c|c|c|}
\hline Trecho & Ponto & $\begin{array}{c}\text { IAF } \\
\left(\mathrm{m}^{2} / \mathrm{m}^{2}\right)\end{array}$ & $\begin{array}{c}\mathrm{MO} \\
\left(\mathrm{g} / \mathrm{dm}^{3}\right)\end{array}$ & RR & Trecho & Ponto & $\begin{array}{c}\text { IAF } \\
\left(\mathrm{m}^{2} / \mathrm{m}^{2}\right)\end{array}$ & $\begin{array}{c}\mathrm{MO} \\
\left(\mathrm{g} / \mathrm{dm}^{3}\right)\end{array}$ & RR \\
\hline \multirow{10}{*}{$\mathrm{a}$} & 1 & 1,830 & 44 & 3,750 & \multirow{10}{*}{ b } & 11 & 1,482 & 51 & 10,000 \\
\hline & 2 & 2,167 & 43 & 5,000 & & 12 & 1,536 & 45 & 10,000 \\
\hline & 3 & 2,092 & 54 & 5,000 & & 13 & 1,058 & 51 & 9,000 \\
\hline & 4 & 2,200 & 53 & 5,000 & & 14 & 1,122 & 50 & 10,000 \\
\hline & 5 & 1,776 & 48 & 5,000 & & 15 & 1,356 & 56 & 10,000 \\
\hline & 6 & 1,683 & 40 & 5,000 & & 16 & 1,495 & 58 & 10,000 \\
\hline & 7 & 1,032 & 50 & 1,667 & & 17 & 0,741 & 34 & 2,500 \\
\hline & 8 & 1,539 & 51 & 6,667 & & 18 & 1,187 & 63 & 5,000 \\
\hline & 9 & 2,228 & 67 & 5,000 & & 19 & 1,002 & 61 & 7,500 \\
\hline & 10 & 1,793 & 55 & 5,000 & & 20 & 1,247 & 66 & 7,500 \\
\hline Média & & 1,834 & 50,500 & 4,708 & Média & & 1,223 & 53,500 & 8,150 \\
\hline Mediana & & 1,812 & 50,500 & 5,000 & Mediana & & 1,217 & 53,500 & 9,500 \\
\hline Desvio padrão & & 0,369 & 7,649 & 1,273 & Desvio padrão & & 0,253 & 9,466 & 2,593 \\
\hline $\begin{array}{c}\text { Coef. de } \\
\text { Variação (\%) }\end{array}$ & & 20,11 & 15,15 & 27,05 & $\begin{array}{c}\text { Coef. de } \\
\text { Variação (\%) }\end{array}$ & & 20,71 & 17,69 & 31,82 \\
\hline \multirow{10}{*}{ c } & 21 & 0,754 & 52 & 8,333 & \multirow{10}{*}{$\mathrm{d}$} & 31 & 1,656 & 37 & 2,500 \\
\hline & 22 & 1,479 & 55 & 1,875 & & 32 & 2,055 & 53 & 15,000 \\
\hline & 23 & 1,383 & 67 & 9,000 & & 33 & 1,598 & 54 & 2,500 \\
\hline & 24 & 0,829 & 64 & 5,000 & & 34 & 1,669 & 43 & 5,000 \\
\hline & 25 & 3,120 & 53 & 10,000 & & 35 & 2,049 & 60 & 10,000 \\
\hline & 26 & 2,087 & 42 & 5,000 & & 36 & 1,993 & 56 & 10,000 \\
\hline & 27 & 1,659 & 57 & 1,250 & & 37 & 1,904 & 53 & 10,000 \\
\hline & 28 & 2,055 & 45 & 3,333 & & 38 & 2,346 & 55 & 6,667 \\
\hline & 29 & 1,856 & 39 & 3,333 & & 39 & 1,434 & 51 & 5,000 \\
\hline & 30 & 2,534 & 36 & 7,500 & & 40 & 1,749 & 46 & 5,000 \\
\hline Média & & 1,776 & 51,000 & 5,462 & Média & & 1,845 & 50,800 & 7,167 \\
\hline Mediana & & 1,758 & 52,500 & 5,000 & Mediana & & 1,827 & 53,000 & 5,834 \\
\hline Desvio padrão & & 0,727 & 10,371 & 3,084 & Desvio padrão & & 0,272 & 6,861 & 3,991 \\
\hline $\begin{array}{c}\text { Coef. de } \\
\text { Variação (\%) }\end{array}$ & & 40,96 & 20,34 & 56,46 & $\begin{array}{c}\text { Coef. de } \\
\text { Variação (\%) }\end{array}$ & & 14,76 & 13,50 & 55,68 \\
\hline
\end{tabular}

Em que: IAF = Índice de Área Foliar; MO = Matéria Orgânica; RR = Índice de Vermelho do Solo; Coef. = Coeficiente.

Em relação aos valores obtidos para o índice RR, observou-se que, no trecho - a, foram obtidos valores entre 1,667 e 6,667, no trecho - b, entre 2,500 e 10,000, no trecho - c, entre 1,250 e 10,000 e no trecho-d, entre 2,500 e 15,000 .

A Tabela 5 revela os valores inferidos ao aplicar o teste $H$ e a determinação do valor "p" nas trilhas e nos trechos da Mata. Para o teste $H$, como a tabela de "qui-quadrado" fornece o valor igual a 5,991 (amostra de tamanho 16 com 2 graus de liberdade) (FREUND, 2006), constata-se que, para as trilhas, os valores de IAF e MO são menores que o da tabela "qui-quadrado", o que leva à não rejeição da hipótese de igualdade de médias dessas duas grandezas. Esse fato pode ser confirmado ao se analisarem os valores "p" das referidas grandezas contidos na mesma tabela ao aplicar Microsoft Office Excel. Nesses casos, constatou-se que os valores são maiores que $5 \%$ do nível de significância.

Entretanto, para a grandeza RR o valor inferido ao aplicar o teste $H$ foi maior que 5,991, ao passo que o valor "p" foi menor que 5 \% do nível de significância, lendo a rejeição da hipótese de igualdade de 
médias. Adicionalmente, neste caso específico, foi feito o cálculo do valor "p" para comparar os grupos dois a dois nas trilhas, de modo a identificar aqueles que diferem da igualdade de médias. Comprovou-se que apenas o grupo com as trilhas II - III acusou rejeição, pois o valor "p" foi 0,0076.

Na mesma sintonia, para o caso dos trechos estudados, a Tabela 5 mostra que aplicando o teste $H$ os valores de IAF e RR são maiores que o da tabela "qui-quadrado", que corresponde a 7,815 (amostra de tamanho 40 com 3 graus de liberdade) (FREUND, 2006), o que leva à rejeição da hipótese de igualdade de médias dessas duas grandezas. A tabela apresenta um valor menor que 7,815 para a grandeza MO, o que implica a sua não rejeição. Aplicando o valor "p" para reforçar as análises estatística, percebe-se a concordância com o teste $H$.

Para a grandeza IAF, os grupos dois a dois dos trechos a-b, b-c e b-d acusaram valor "p" menores que $5 \%$ do nível de significância $(0,0004 ; 0,0357$ e 0,0001, respectivamente), acusando a rejeição da hipótese de igualdade de médias nesses trechos. Da mesma forma, para o RR, os trechos a-b e b-c também revelaram valor "p" menores que $5 \%$ do nível de significância, nesses casos 0,0014 e 0,0492, respectivamente, o que levou à rejeição da hipótese de igualdade de médias.

TABELA 5: Valores obtidos aplicando o teste $H$ e o teste valor " $p$ ” para IAF, MO e RR.

TABLE 5: Values obtained by applying the test $H$ and the test " $p$ " value for IAF, MO and RR.

\begin{tabular}{ccccc}
\hline Teste & Região & IAF & MO & RR \\
\hline \multirow{2}{*}{$\mathrm{H}$} & Trilhas & 0,011 & 2,266 & 7,279 \\
& Trechos & 13,256 & 0,704 & 9,286 \\
\hline \multirow{2}{*}{ valor "p" } & Trilhas & 0,941 & 0,789 & 0,016 \\
& Trechos & 0,009 & 0,859 & 0,048 \\
\hline
\end{tabular}

Comparando-se o parâmetro IAF para os pontos localizados nas três trilhas do interior e nos quatro trechos da borda do remanescente florestal, como apresentado na Figura 3a, constata-se uma variação entre 0,955 e $3,522 \mathrm{~m}^{2} / \mathrm{m}^{2}$ no interior, sendo que $63 \%$ dos valores encontraram-se abaixo da média de $2,097 \mathrm{~m}^{2} /$ $\mathrm{m}^{2}$. No entanto, os valores para esse mesmo parâmetro, obtidos especificamente para a borda, encontraram-se dentro da faixa de 0,741 e $3,120 \mathrm{~m}^{2} / \mathrm{m}^{2}$, com $50 \%$ dos valores abaixo da média de $1,669 \mathrm{~m}^{2} / \mathrm{m}^{2}$ (Figura 3a).

A Figura $3 b$ apresenta a distribuição dos valores obtidos para concentração de MO tanto no interior como na borda do remanescente em estudo. Nesta figura, aplicando-se o mesmo tipo de análise estatística utilizada anteriormente, é possível verificar que o índice MO para os pontos do interior apresentou oscilação entre 21,000 e $74,000 \mathrm{~g} / \mathrm{dm}^{3}$, sendo que $52 \%$ dos valores encontraram-se abaixo da média de $39,000 \mathrm{~g} / \mathrm{dm}^{3}$. Entretanto, os valores obtidos para a borda registraram-se dentro da faixa de 34,000 e $67,000 \mathrm{~g} / \mathrm{dm}^{3}$, com $37,5 \%$ dos valores abaixo da média de $51,450 \mathrm{~g} / \mathrm{dm}^{3}$ (Figura $5 \mathrm{~b}$ ), confirmando que o solo é predominantemente argiloso na ARIE estudada.

Para o índice de vermelho (RR) observa-se que nos pontos do interior foram registradas variações entre 1,000 e 11,250 , sendo que $53 \%$ dos valores encontraram-se abaixo da média de 5,862 , enquanto que para os valores dos pontos localizados na borda foi identificada variação dentro da faixa de 1,250 e 15,000, com $55 \%$ dos valores abaixo da média de 6,372 (Figura 3c). Várias peculiaridades sobre a cor dos solos, no que diz respeito aos fatores que influenciam sua obtenção (umidade, poder de revestimento e pigmentação de determinados constituintes - minerais ou orgânicos) são apresentadas no trabalho realizado por Campos e Demattê (2004).

De acordo com os critérios de cor recomendados pelo Sistema Brasileiro de Classificação de Solos (SiBCS), observou-se a correspondência entre a nomenclatura da cor do horizonte diagnóstico do solo e $\mathrm{RR}$, de forma que: a) $\mathrm{RR}<5$ implica em solos amarelos; b) $5 \leq \mathrm{RR}<9$, indica solos vermelho-amarelos; e c) solos com $R R \geq 9$, refere-se a solos vermelhos. Desta maneira, como se pode comprovar na Figura 3c, 47 \% dos dados amostrados no interior da Mata de Santa Genebra apresentaram classificação "vermelhoamarelo". Os 53 \% restantes dividem-se em "amarelo" (32\%) e "vermelho" (21\%). No entanto, para a borda do remanescente inferiu-se que 57 \% das amostras apresentaram classificação "vermelho-amarelo", $23 \%$ das amostras foram classificadas pertencentes à classe "vermelho" e os $20 \%$ restantes possuem 
classificação "amarelo".
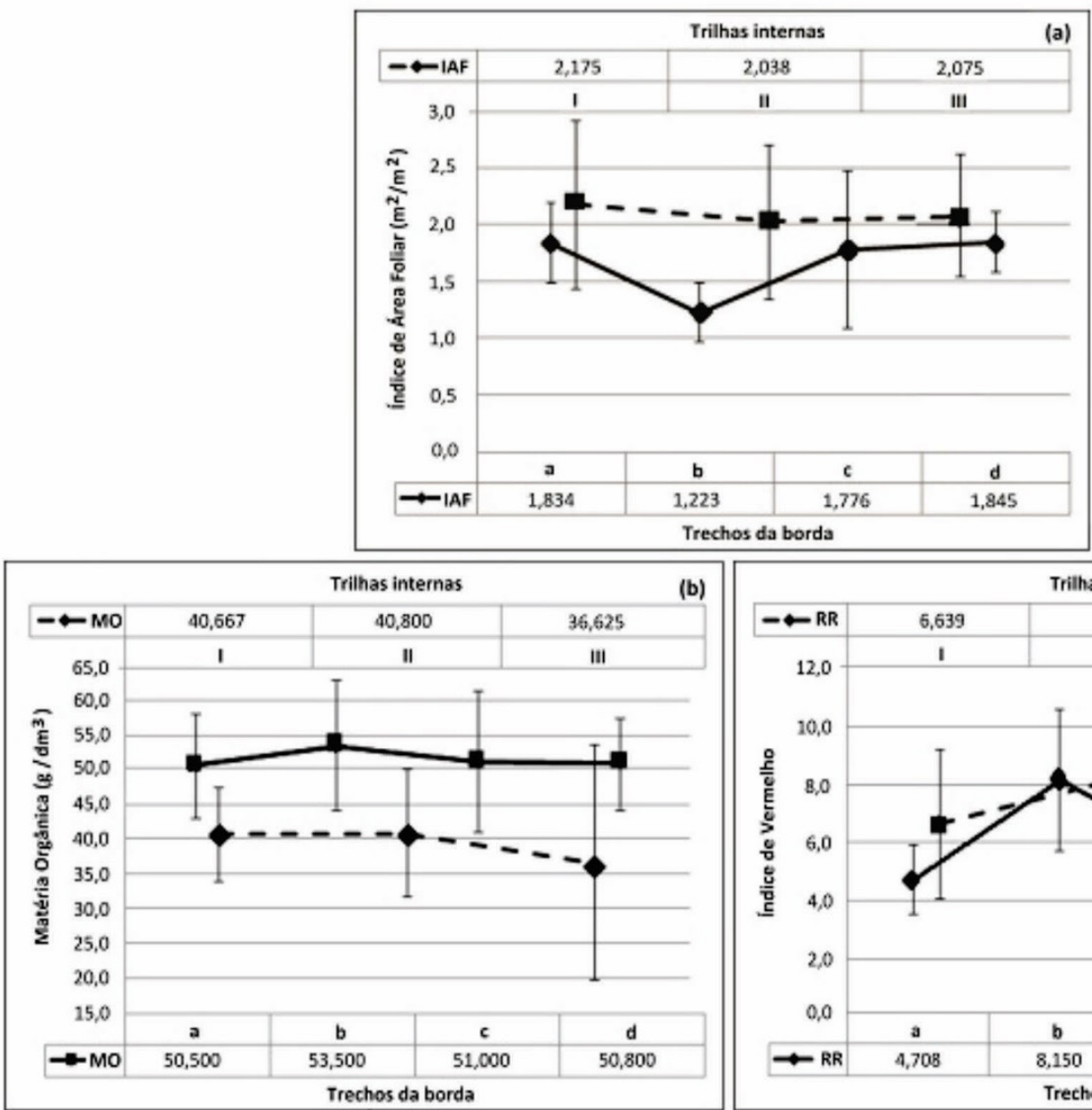

(b)

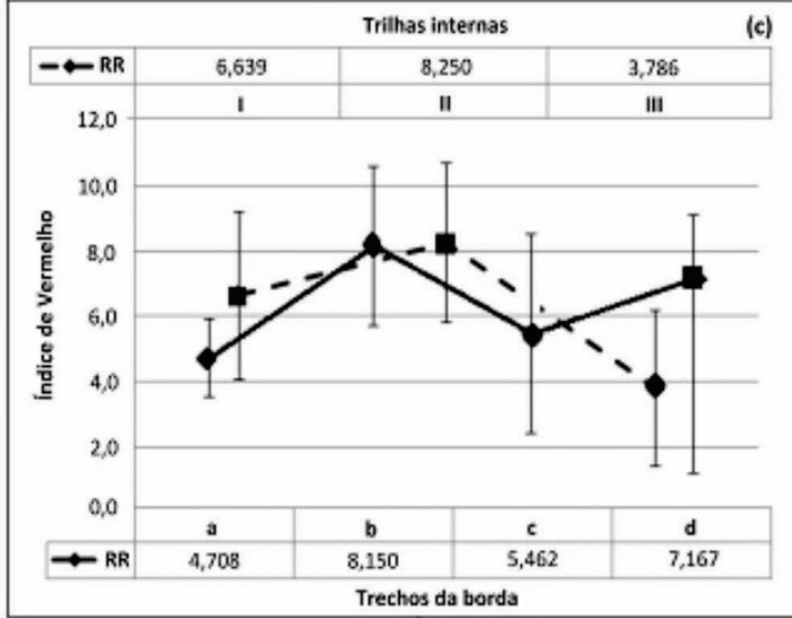

FIGURA 3: Comparações do: (a) Índice de Área Foliar, (b) Matéria Orgânica e (c) Índice de Vermelho, entre as áreas da borda e internas à Mata de Santa Genebra.

FIGURE 3: Comparisons of: (a) Leaf Area Index, (b) Organic Matter and (c) Red Index, between the border areas and inside Mata de Santa Genebra.

Assim, e em consonância com o estudo de Santana et al. (2013), os valores referentes ao estoque de carbono na vegetação e ao índice de vermelho são maiores em regiões onde há a presença de vegetação mais densa. Neste contexto, as Figuras 4 e 5 e a Tabela 6 trazem as análises de correlações entre o IAF, o teor de matéria orgânica (MO) e o índice de vermelho (RR).

Ao realizar as combinações dos três parâmetros no interior da mata (Figura 4) e na borda (Figura 5), constatou-se que o comportamento entre as variáveis não está em sintonia nas regiões do remanescente florestal. Isso pode ser comprovado nas referidas figuras, visto que as flutuações registradas no comportamento da MO (barras dos histogramas) não aumentam ou diminuem com os correspondentes em IAF (gráficos em linhas sólidas) e RR (gráficos em linhas tracejadas), e vice-versa, apresentando também baixa correlação se analisar a Tabela 6. Neste sentido, para os dados tratados no interior da mata, o coeficiente de correlação entre IAF-MO foi 0,124, entre IAF-RR foi 0,362 e entre MO-RR foi de 0,017 , o que não indica haver correlações entre essas grandezas. O mesmo obteve-se para a borda, com valores do coeficiente de correlação entre IAF-MO, IAF-RR e MO-RR, foram de 0,149, 0,112 e 0,279, respectivamente.

Ao se tratar da relação matéria orgânica e cor do solo, verifica-se no presente trabalho que estes dois parâmetros estão diretamente relacionados entre si, corroborando com o resultado verificado por Fontes e Carvalho Junior (2005). Assim, para medidas inferidas de comportamento crescentes no valor da cor (croma), o teor de matéria orgânica diminui. Esse comportamento pode ser verificado nas cores da Carta de 
Munsell, cujos valores mais elevados do valor de cor (croma) em solos de cores mais claras correspondem geralmente a menores teores de matéria orgânica (DEMATTÊ et al., 2011). Os pontos que apresentaram maior teor de matéria orgânica, como a amostra no ponto " $N$ " (trilha - III; Barone-2) do interior da mata com valor igual a $74 \mathrm{~g} / \mathrm{dm}^{3}$ (Figura 4), apresentou coloração escura que, de acordo com a Carta de Munsell, representa uma característica de solo com teor elevado de matéria orgânica e, possivelmente, com boas condições de fertilidade e grande atividade microbiana, justificando o explicitado na literatura (MUNSELL SOIL COLOR COMPANY, 1975).

TABELA 6: Coeficientes de correlação entre IAF, MO e RR medidos na Mata de Santa Genebra.

TABLE 6: Correlation coefficients between IAF, MO and RR measured in Mata de Santa Genebra.

\begin{tabular}{ccccc}
\hline Região & Posição & IAF x MO & IAF x RR & MO x RR \\
\hline \multirow{4}{*}{ Trilhas } & I & 0,450 & 0,341 & 0,256 \\
& II & 0,360 & 0,325 & 0,304 \\
& III & 0,298 & 0,664 & 0,271 \\
& Todas & 0,124 & 0,362 & 0,017 \\
\hline \multirow{5}{*}{ Trechos } & a & 0,301 & 0,517 & 0,121 \\
& b & 0,311 & 0,752 & 0,232 \\
& c & 0,525 & 0,218 & 0,121 \\
& d & 0,530 & 0,621 & 0,562 \\
& Todas & 0,149 & 0,112 & 0,279 \\
\hline
\end{tabular}

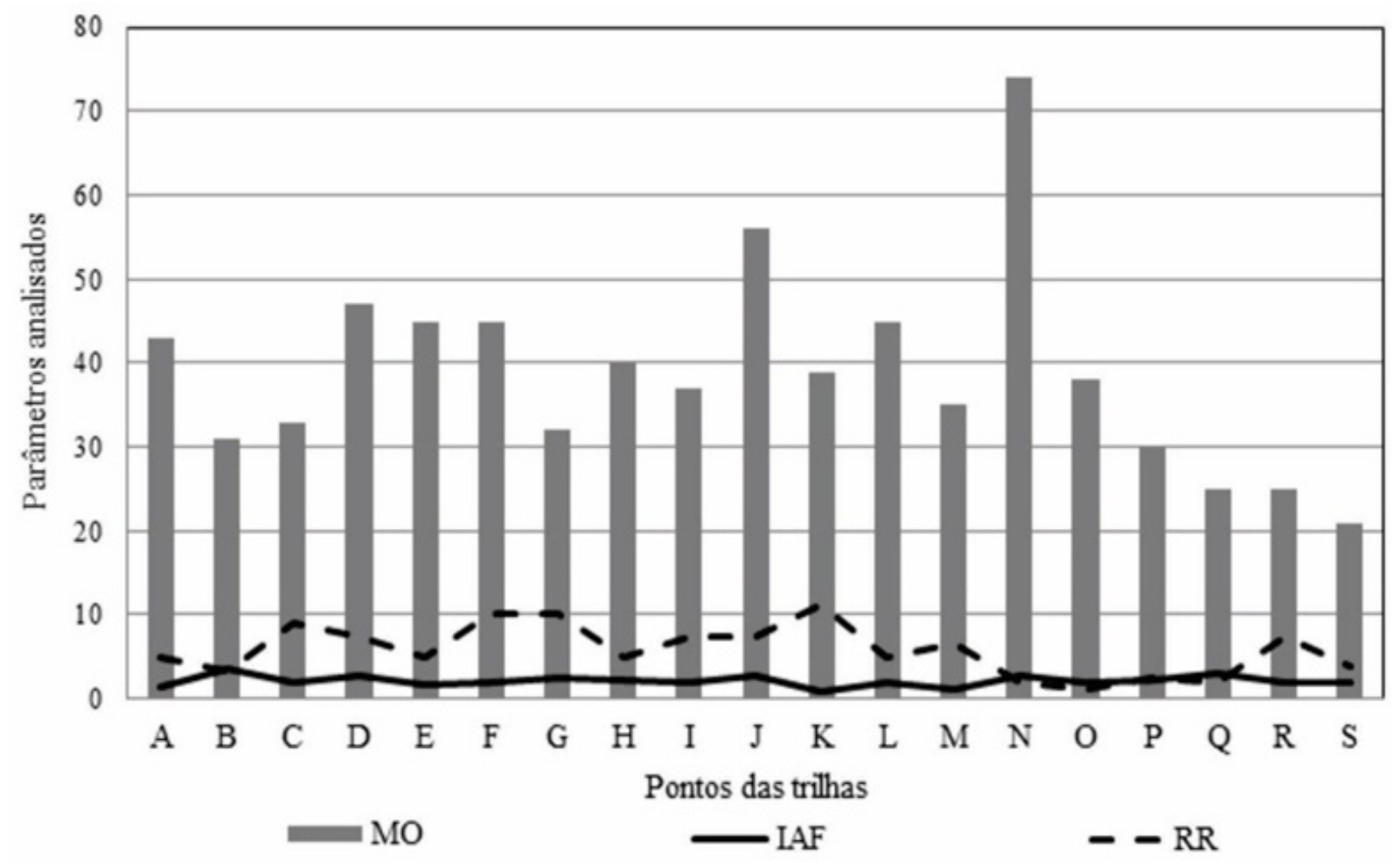

FIGURA 4: Relação Matéria Orgânica (MO) e Índice de Área Foliar (IAF) nos pontos amostrados no interior da Mata de Santa Genebra.

FIGURE 4: Regarding Organic Matter (MO) and Leaf Area Index (IAF) in points sampled within Mata de Santa Genebra. 


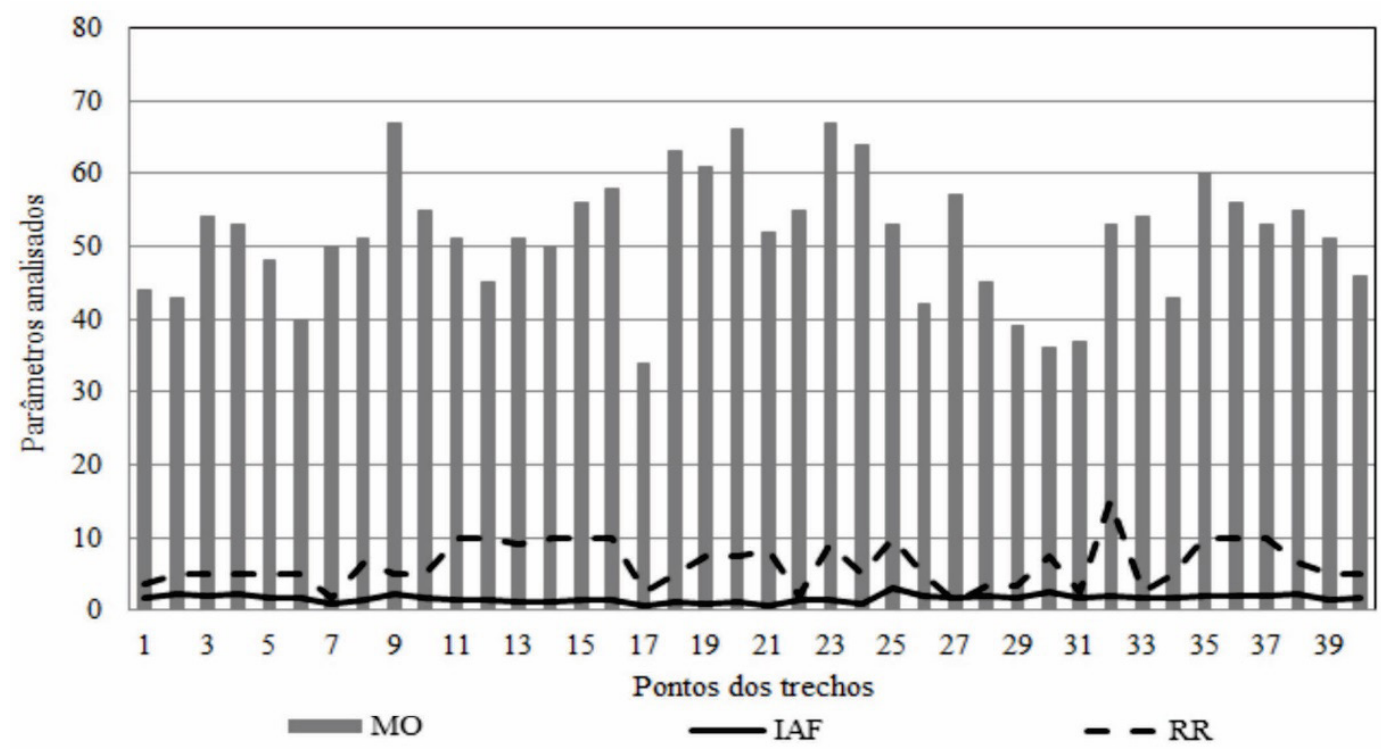

FIGURA 5: Relação Matéria Orgânica (MO) e Índice de Área Foliar (IAF) nos pontos amostrados na borda da Mata de Santa Genebra.

FIGURE 5: Regarding Organic Matter (MO) and Leaf Area Index (IAF) in points on the edge of Mata de Santa Genebra.

Como perspectiva, recomenda-se realizar os mesmos procedimentos aqui discutidos e calculados, em dados coletados nos mesmos pontos da Mata de Santa Genebra, porém, em períodos que envolvam as outras estações do ano. Isso possibilitará realizar análises sazonais mais concisas visando à verificação de possíveis correlações entre os parâmetros aqui averiguados. Assim, como constataram Rody et al. (2014), que inferiram valores de IAF mais baixos durante o período seco nas diferentes situações estudadas, indicando uma sensibilidade do equipamento com base na variação sazonal.

\section{CONCLUSÃO}

Os resultados obtidos neste trabalho permitem concluir que:

a) Por meio de análises do Índice de Área Foliar, as áreas de borda do remanescente florestal se encontram mais degradadas que o seu interior, sendo possível observar maiores valores de IAF nos trechos internos da mata do que nas áreas de borda;

b) As fotográficas hemisféricas auxiliaram de forma positiva na avalição da qualidade ambiental das áreas de bordas de remanescentes, uma vez que destacaram os trechos que apresentaram os menores valores de IAF de forma não destrutiva e sem necessidade de coleta direta de material de planta e solo;

c) Não foi encontrada correlação entre o Índice de Área Foliar (IAF), a Matéria Orgânica (MO) e o Índice de Vermelho (RR), porém, existe uma relação direta entre o Índice de Matéria Orgânica e a Cor do Solo.

\section{AGRADECIMENTOS}

Os autores agradecem a FAPESP (Fundação de Amparo à Pesquisa do Estado de São Paulo) pelo apoio financeiro, a FAPIC (Fundação de Amparo à Pesquisa de Iniciação Científica - PUC-Campinas) pelas concessões das bolsas de Iniciação Científica e a equipe de profissionais da Mata de Santa Genebra pelo apoio em campo e infraestrutura disponibilizada. 


\section{REFERÊNCIAS}

AGUiAR, G. D. Caracterização dos solos da Mata de Santa Genebra, Campinas, SP. 1995. Relatório de Estágio (Graduação) - Faculdade de Engenharia da Universidade Estadual de Campinas, Campinas, 1995. Disponível em: <http://www.icmbio.gov.br/portal/images/stories/imgs-unidades-conservação/arie_ mata_de_santa_genebra.pdf $>$. Acesso em: 10 dez. 2015.

BADIRU, A. I. Método para a classificação tipológica da floresta urbana visando o planejamento e a gestão das cidades. In: SIMPÓSIO BRASILEIRO DE SENSORIAMENTO REMOTO, INPE, 12., 2005, Goiânia. Anais... Goiânia: INPE, 2005. v. 1. p. 1427-1433.

BRASIL. Ministério do Meio Ambiente. Plano de manejo: A.R.I.E. Mata de Santa Genebra. Campinas: MMA, 2010. Disponível em: <http://www.icmbio.gov.br/portal/images/stories/imgs-unidades-coservacao/ arie_mata_de_santa_genebra.pdf $>$. Acesso em: 07 abr. 2016.

CHUDNOBSKY, J. et al. Proposta de recuperação paras as áreas de borda do remanescente florestal urbano ARIE Mata de Santa Genebra - Campinas/SP. In: CONGRESSO BRASILEIRO DE GESTÃO AMBIENTAL, 6., 2015, Porto Alegre. Anais... Porto Alegre: IBEAS, 2015. Disponível em: <http://www. ibeas.org.br/congresso/Trabalhos2015.pdf>. Acesso em: 10 jan. 2016.

BOTELHO, M. R. et al. Medida da cor em solos do Rio Grande do Sul com a carta de Munsell e por calorimetria. Ciência Rural, Santa Maria, v. 36, n. 4, p. 1179-1185, 2006.

CAMPOS, R. C.; DEMATTÊ, J. A. M. Cor do solo: uma abordagem da forma convencional de obtenção em oposição à automatização do método para fins de classificação dos solos. Revista Brasileira de Ciência do Solo, Viçosa, MG, v. 28, n. 5, p. 853-863, 2004.

DAMAME, D. M. et al. Variation of the anthropic vulnerability in Ribeirão das Pedras watershed in Campinas/SP-Brazil.Geophysical Research Abstract, [s. 1.], v. 17, p. 577, 2015.

DEMATTÊ, J. A. M. et al. Quantificação de matéria orgânica do solo através de modelos matemáticos utilizando calorimetria no sistema Munsell de cores. Bragantia, Campinas, v. 70, n. 3, p. 590-597, 2011.

EMBRAPA. Manual de métodos de análises de solo. 2. ed. Rio de Janeiro: Centro Nacional de Pesquisa de Solos, 2011. 225 p. Disponível em: < http://www.cnps.embrapa.br/download/manual_metodos_analise_ solo.zip>. Acesso em: 4 jul. 2012.

ETTO, T. L. et al. Ecologia da paisagem de remanescentes florestais na bacia hidrográfica do Ribeirão Das Pedras - Campinas-SP. Revista Árvore, Viçosa, MG, v. 37, n. 6, p. 1063-1071, 2013.

FENGLER F. H. et al. Qualidade ambiental dos fragmentos florestais na Bacia Hidrográfica do Rio JundiaíMirim entre 1972 e 2013. Revista Brasileira de Engenharia Agrícola e Ambiental,Campina Grande, v. 19, n. 4, p. 402-408, 2015.

FONTES, M. P. F.; CARVALHO JUNIOR, I. A. Color attributes and mineralogical characteristics, evaluated by radiometry, of highly weathered tropical soils. Soil Science SocietyofAmericaJournal, Madison, v. 69, p. 1162-1172, 2005.

FREUND, J. E. Estatística aplicada: economia, administração e contabilidade. 11. ed. Porto Alegre: Bookman, 2006. 536 p.

GALVANI, E.; LIMA, N. G. B. Fotografias hemisféricas em estudos microclimáticos: referencial teóricoconceitual e aplicações. Ciência e Natura, Santa Maria, v. 36, nesp, p. 215-221, 2014.

GUERRA, A. J. T. O papel da matéria orgânica e dos agregados na erodibilidade dos solos. Anuário do Instituto de Geociências, Rio de Janeiro, v. 13, n. 4, p. 43-52, 1990.

HEMIVIEW. Hemiview user manual. Cambridge: Delta-t Devices, 2015. 85 p. Disponível em: $<\mathrm{ftp}: / / \mathrm{ftp}$. dynamax.com/manuals/HemiView_Manual.pdf>. Acesso em: 24 out. 2015.

InSTITUTO AGRONÔMICO DE CAMPINAS. Centro de Pesquisa e Desenvolvimento de Solos e Recursos Ambientais. [2015].Disponível em: $<$ http://www.iac.sp.gov.br/produtoseservicos/analisedosolo/ interpretacaoanalise.php>. Acesso em: 15 out. 2015.

JONCKHEERE, I. et al. Review of methods for in situ leaf area index determination: Part I. theories, sensors and hemispherical photography. Agriculture Forest Meteorology, Connecticut, v. 121, n. 1 p. 19-35, 2004.

JENNINGS, S. B. et al. Assessing forest canopies and understorey illumination: canopy closure, canopy cover and other measures. Forestry, Oxford, v. 72, n. 1, 1999. 
LAMPRECHT, H. Silvicultura nos trópicos: ecossistemas florestais e respectivas espécies arbóreas possibilidades e métodos de aproveitamento sustentado [Waldbau in dentropen]. Rossdorf: TZ-Verl. Ges. (GTZ), 1990. 343 p.

LEMOS, R. C.; SANTOS, R. D. Manual de descrição e coleta de solo no campo. 3. ed. Campinas: Sociedade Brasileira de Ciência do Solo; Centro Nacional de Pesquisa de Solos, 1996. 83 p.

LONGO, R. M. et al. Environmental impact assessment of the surrounding areas of urban forests, WIT Transactions on Ecology and the Environment, Southampton, v. 193, p. 501-508, 2015.

MENDES, D. R. et al. Caracterização físico-química do solo em Área de Relevante Interesse Ecológico (A.R.I.E.) - Mata de Santa Genebra - Campinas/SP. In: CONGRESSO BRASILEIRO DE GESTÃO AMBIENTAL, 4., 2013, Salvador. Anais... Salvador: IBEAS, 2013. v. 1. p. 1-13. Disponível em: < http:// www.ibeas.org.br/congresso/Trabalhos2013/VI-044.pdf>. Acesso em: 13 nov. 2015.

MUNSELL SOIL COLOR COMPANY. Munsell soil color charts. Baltimore: Munsell products, 1975. v. 1. $117 \mathrm{p}$.

PAIVA, H. N.; GONÇALVES, W. Florestas urbanas: planejamento para melhoria da qualidade de vida. Viçosa, MG: Aprenda Fácil, 2002. 177 p. (Série Arborização Urbana, n. 2).

PRIMACK, R. B. Essentials of conservation biology. Sunderland: Sinauers Associates, 2006. 586 p.

RODY Y. P. et al. Estimates of the Leaf Area Index (LAI) using LAI-2000 and hemispherical photos in Eucalyptus plantations. CiênciaFlorestal, Santa Maria, v. 24, n. 4, p. 925-934, out./dez. 2014.

ROXBURGH, J. R.; KELLY, D. Short communication uses and limitations of hemispherical photography for estimating forest light environments. New Zealand Journal of Ecology, New Zealand. v. 19, n. 2, p. 213-217, 1995.

SANCHES, L. et al. Índice de área foliar em floresta de transição Amazônia cerrado em diferentes métodos de estimativa. Ciência e Natura, Santa Maria, v. 30, n. 1, p. 57-69, 2008.

SANTANA, O. A. et al. Relação entre o índice de avermelhamento do solo e o estoque de carbono na biomassa aérea da vegetação de cerrado. Ciência Florestal, Santa Maria, v. 23, n. 4, p. 783-794, 2013.

SOUZA, Z. M.; SOUZA, G. S. Número de amostras e seus efeitos na análise geoestatística e krigagem de atributos do solo. In: SIMPÓSIO DE GEOESTATÍSTICA EM CIÊNCIAS AGRÁRIAS, 2., 2011, Botucatu. Anais... Botucatu: SGeA, 2011. Disponível em <http://www.fca.unesp.br/sgea/Docs2011/41.pdf > . Acesso em: 10 jun. 2016.

TORRENT, J.; BARRÓN, V. Laboratory measurement of soil color: theory and practice. In: BIGHAM, J. M.; CIOLKOSZ, E. J. (Ed). Soil color. Madison: Soil Science SocietyofAmerica, 1993. p. 21-33. (SpecialPublication, 31).

VILANI, M. T. et al. Estimativa do Índice de Área Foliar pelo método de Lambert-Beer e produto do sensor MODIS em uma floresta de transição Amazônia - Cerrado. In: CONGRESSO BRASILEIRO DE AGROMETEOrologiA, 16., 2009, Belo Horizonte. Anais... Belo Horizonte: S. B. AGRO., 2009. Disponível em: <http://www.sbagro.org.br/anais_congresso_2009/cba2009/044.pdf > Acesso em: 22 out. 2015.

ZHANG, Y. et al. Determining digital hemispherical photograph exposure for leaf area index estimation. Agricultural and Forest Meteorology, Amsterdam, v. 133, p. 166-181, 2005. 